\title{
Reversing the stigma towards international migrants: The role of public health professionals
}

\author{
Ozge KARADAG CAMAN ${ }^{1}$ D, Selma KARABEY² (D)
}

${ }^{1}$ Center for Sustainable Development, Earth Institute, Columbia University, New York, U.S.A.

${ }^{2}$ Department of Public Health, Faculty of Medicine, Istanbul University, Istanbul, Turkey.

\author{
Corresponding Author: Ozge KARADAG CAMAN
}

E-mail:ok2267@columbia.edu

\begin{abstract}
Objective: Stigma is one of the most significant challenges that international migrants face in their host societies. Stigma can exist at individual, interpersonal, and structural levels, and studies show that stigma towards migrants occur everywhere around the world with varying degrees. This study aimed to review existing literature on health effects of stigma towards international migrants and the role public health professionals can play to reduce stigma and its negative health outcomes for both economic and forced migrant populations.

Materials and Methods: This narrative review was prepared by searching existing scientific literature in English and Turkish, in addition to available international reports and guidelines on best practices aiming to reduce stigma towards international migrants and its detrimental effects on migrant health.

Results: Stigma and discrimination remain significant public health challenges across diverse cultural environments and have detrimental effects on mental, social and physical health. International migrants usually face double burden in accessing health care due to language, economic, legal, structural, and other barriers, which are excacerbated by stigma and discrimination in health care settings.

Conclusion: Reversing the stigma towards international migrants requires multifaceted, multisectoral and long-term efforts, which should have social, cultural, educational, legal and institutional dimensions. Public health professionals have a strong potential to lead such joint initiatives at the local, national and global level. Targeted interventions for key professional groups are essential, however, wider educational interventions that start in pre-school years and aim to build more inclusive societies in a more sustainable way seem more crucial.

Keywords: Social discrimination, Migrants, Refugees, Mental health, Public health
\end{abstract}

\section{INTRODUCTION}

International migration, which can be voluntary, forced or in mixed forms has a tendency to increase all around the world due to factors such as globalization, conflicts, climate change and wider opportunities of electronic communication and easier transportation. Today, the number of people, who live in a country other than their country of origin, has exceeded 250 million, whereas the number of forced migrants including refugees and asylum seekers is nearly 70 million [1].

Most international migrants, but especially forced migrants usually lose previous social support systems in their countries of origin and face challenges with respect to optimum living conditions, access to health care, social care, education and employment opportunities in their host countries [2]. Stigma and discrimination is usually another significant challenge that most migrants face in their host societies.

Stigma can exist at individual, interpersonal, and structural levels [3]. Individual stigma refers to the psychological processes in which individuals engage in response to stigma, such as concealment and self-stigma (i.e., the internalization of negative societal views about a certain group). In contrast, interpersonal stigma refers to interactions that occur between the stigmatized and non-stigmatized individuals or population groups. The stigma concept has recently been expanded beyond the individual and interpersonal levels to broader, macrosocial forms, termed structural stigma [4,5]. Hatzenbuehler and Link (2014) offered a working definition of this relatively new construct: "societal-level conditions, cultural norms, and institutional policies that constrain the opportunities, resources, and wellbeing of the stigmatized" [6].

In general, most stigmatized population groups are minority groups such as ethnic minorities, religious minorities, people with low socio-economic status, asylum seekers, refugees and economic migrants, persons living with mental or physical disabilities, persons living with HIV (PLHIV) or other 
infections such as people affected by neglected tropical diseases, sexual minorities, sex workers, homeless people, persons with alcohol and/or substance use problems, as well as incarcerated populations $[7,8]$.

Studies show that stigma and discrimination towards international migrants occur everywhere around the world with varying degrees, although the reported prevalence rates differ across studies, mainly because of differences in measurement of stigma and discrimination (perceived vs. enacted stigma; validated scales vs. invalidated questionnaires, etc.). This study aimed to review existing literature on health effects of stigma towards international migrants and the role public health professionals can play to reduce stigma and its negative health outcomes for migrant populations including economic and forced migrants.

\section{MATERIALS and METHODS}

This narrative review was prepared by searching existing scientific literature in English and Turkish, in addition to available international reports and guidelines on best practices aiming to reduce stigma towards international migrants and its detrimental effects on migrant health. The search terms used in various combinations were as follows; "stigma", "discrimination", "migrant", "refugee", "asylum seeker", "health" and "health care".

The article reviewed the field of research on and interventions to reduce stigma as it relates to international migrants' health through addressing three specific issues: (i) describing health related consequences of stigma towards migrants in a multidimensional manner; (ii) providing examples of interventions to reduce stigma towards migrants for promoting their health and improving quality of health care; and (iii) outlining future directions for public health and other health professionals to advance scientific literature and advocate for evidence based interventions in this field.

\section{RESULTS}

\section{Health effects of stigma}

Stigma and discrimination remain public health challenges across diverse cultural environments and have detrimental effects on mental, social and physical health at the individual and community levels. Like other aspects of society, stigma also affects health care settings and the quality of health care. Despite regulations and codes of practices for universal health coverage and inclusion of vulnerable, disadvantaged or marginalized groups in health care, experiences from across the world show that health care is not always at equal distance from different subgroups of a population [7-10].

There is a vast array of scientific literature that includes quantitative, qualitative and mixed approach studies in different health care contexts. Almost all these studies conclude that even in the absence of legal, economic, language and other barriers in accessing health care, certain population groups face stigma related barriers in accessing reliable health information and quality health care [9-11].

According to existing literature, some of the health effects of stigma and discrimination are as follows;

Social health effects: Decline in social support, social networks and social function

Mental health effects: Depression, anxiety disorders, tobacco, alcohol and substance abuse

Physical health effects: Psychosomatic disorders, immune system disorders, problems with either early diagnosis of existing health conditions or overdiagnosis, and worsening prognosis of existing health conditions because of access and/ or quality problems regarding treatment and rehabilitation $[7,8]$.

\section{Double burden faced by international migrants}

Migrants usually face double burden in accessing health care due to language, economic, legal, structural, and other barriers, which are excacerbated by stigma and discrimination in health care settings. Stigma towards international migrants not only affects access to available services, but also negatively affects migrants' coping mechanisms to overcome other migration related problems, and decreases their chances of healthy integration with the host society.

It is widely known that today, the majority of forced migrants are located in low and middle income countries with limited resources for mental health care. This fact, combined with relatively higher prevalence of mental problems, lower level of mental health care seeking behavior and problems in accessing mental health care lead to a significant and hidden mental health burden among migrants, with detrimental and usually undefined effects on host societies and their resources [12].

In many parts of the world, migrants are often disadvantaged in terms of health and access to health care including preventive interventions, relative to the majority of the host populations. A study conducted in China with internal rural-urban migrants showed that migrants experienced social exclusion that may have significant mental health implications. The study found strong evidence that social exclusion was negatively associated with migrants' mental health: limited access to full labor rights and experience of social stigma, discrimination and inequity were the most significant factors [13]. A study with Latino immigrants in the United States showed that immigrants were disproportionately affected by HIV and difficulties in accessing HIV care. In this qualitative study, HIV-infected Latino immigrants experienced significant challenges that led to interruptions in HIV care [14]. Another study, which examined migrant stigma and its effect on social capital reconstruction among migrants in China indicated that social stigma towards migrants is common in urban China and is reinforced through media, social institutions, their representatives, and their day-today interactions. The study found that stigma towards migrant workers created inequalities, undermined trust, and reduced opportunities for interpersonal interactions between migrants and urban residents. The authors stated that through these social processes, social stigma interfered with the reconstruction of 
social capital and that the interaction between stigma and social capital reconstruction presented as a mechanism by which migration led to negative health consequences [15].

Despite the healthy migrant effect, especially for economic or labor migrants, there are certain health disadvantages caused by numerous factors including different ethnicity, language, culture, and religious beliefs, in addition to stigma associated with these factors. The health disadvantages are also explained to a substantial part by the same social determinants that also operate on the host populations. For instance, factors such as education, employment opportunities, housing conditions, acquaintance with the situation in the host country, and legal status, may add to being an international migrant.

Literature shows that international migration may have adverse effects on health, partially depending on the legal and work status of the migrant, but also on the process that has led to migration. Sousa et al. showed that immigrant workers in Spain were more likely to perceive their health as poor than Spanishborn workers. Undocumented migrants mostly report a poorer self-rated and mental health, in particular male migrants $[16,17]$. Therefore, besides designing culturally appropriate and stigma-free health care for international migrants, there is also a need to increase existing efforts to have more inclusive migrant policies, to improve legal status and rights of migrants, and to tackle social determinants of health associated with health inequalities $[17,18]$. It is also important for researchers to adjust their analysis for age, educational level, socioeconomic status and other social determinants of health, when studying stigma and discrimination related health care access and/or health outcomes among migrant populations.

\section{Interventions to reduce stigma towards international migrants}

United Nations organizations emphasize that international migration should not be viewed as a problem to be solved, but a human reality that needs to be managed by countries. In this regard, international communication, collaboration and exchange of best practices seem crucial. Numerous reports indicate that health of migrant communities and health of host societies are interrelated and cannot be managed alone or in separation from the other. This is especially true for mental health, because mental health of migrants is not only important for migrants themselves, but also important for i) mental health of host societies, ii) social health in host countries, and iii) human and financial resources of the host countries [12].

Efforts to promote health for both migrant and host communities not only includes improving access to health information, health education and health services, but also includes promotion of healthy environmental conditions. In this regard, a health promoting environment can only be possible if it is free of stigma and discrimination. Therefore, interventions to decrease stigma and discrimination should include educational, social, cultural, legal and institutional measures for the society as a whole, in addition to support mechanisms for individuals and families negatively affected by stigma. Policy makers and service providers should always take into consideration that mental health of migrants, mental health of host communities, and mental health of professionals serving those communites are all linked, therefore, there should always be a "One Mental Health" approach covering the population as a whole in a given host country, with general and targeted interventions to create a stigma-free and mental health promoting environment for all [12].

Public health approach is based on equity principles and promotes delivery of health care in an equitable manner with special emphasis on social inclusion, hence public health professionals are among the ideal professional groups that can work to decrease stigma and its detrimental effects in societies and in health care settings. Public health professionals also have the advantage of being trained in such a way that thay can play leadership roles in development of multidimensional and interdisciplinary interventions.

Although, combatting stigma at the population level requires a multilevel and multisectoral approach and long-term commitment, smaller-scale interventions have also been shown to have a significant impact on reducing stigma in communities, especially among more clearly defined target groups. Health professionals, education professionals, legal professionals, and media professionals are among the most important professional groups that can create multiplier effects, and thus affect the population as a whole.

Planning, implementing and evaluating anti-stigma interventions will generally require measuring stigma related attitudes and behaviors in those professional groups selected for specific interventions. While validated scales help with more precise quantitative measurements and comparison among different groups or time periods, qualitative methods such as in-depth interviews and focus group discussions can lead to a deeper understanding of stigma related dynamics, as well as barriers and facilitators in promoting stigma free attitudes and behaviors.

Among numerous studies conducted so far, one example of such a targeted study was conducted with last year medical students in Turkey [19]. The study findings showed that one third of future physicians were uncomfortable in providing health services for refugees and migrants and eight out of ten students felt that their knowledge and skills were inadequate in approaching different vulnerable groups. Almost all last year students reported a strong need to make necessary curriculum changes for medical students to gain specific knowledge and skills for approaching vulnerable/disadvantaged population groups and in combatting stigma and discrimination in health care settings [19].

Available data indicate that there are no standard and widely used educational programs to combat stigma among health professionals, however, there are examples for best practices in different regions of the world, which provide evidence base for future larger scale educational interventions. One such example is an elective internship program entitled "Public Health, Vulnerable Groups, Society and Physicians" by Istanbul University, Faculty of Medicine, Department of Public Health. 
This program for forth year medical students aims to strengthen medical education on social aspects of health, where students discuss and find solutions for health and/or social problems faced by individuals and communities that are stigmatized or marginalized. This unique educational program includes interactive training methods such as small group work, large group discussion, role-play, institutional visits, home visits, keeping a training diary, preparing a seminar, in addition to project development, and has been implemented in collaboration with local social care services and non-governmental organizations in Istanbul [20]. Some of the feedback received from students during evaluation of the program were as follows:

"I returned home with a lot of questions in my mind and hands on field experience. I believe this program will motivate me to read a lot on social issues".

"This is the first time that I'm faced with social aspects of medicine in such a systematic way. I think this kind of work is as important as saving a patient's life."

"I will remember this experience and the living conditions of vulnerable people for a long time. I would like to be in the field again. Thank you for giving me the opportunity to realize this side of medicine."

"In my point of view, the most significant contribution of this program was that I'm now aware that medicine is not a profession that can only be practiced in clinics. We need to question the root causes that bring patients to hospitals." [20].

Another educational intervention example is an elective course for first year medical students at Hacettepe University. This 14 weeks course was designed by psychiatry and public health faculty for students to understand the dynamics and health effects of stigma as well as learn more about different stigmatized population groups and discuss interventions to overcome stigma in health care settings. This course also uses interactive training methods such as brainstorming, small group work, role-play, simulation, film showing, self-disclosure of lived experiences, large group discussion, and project design.

The course is run by faculty from different disciplines and students have the chance to interact with different vulnerable groups and their families, such as refugees, PLHIV, sexual minorities, persons with mental or physical disabilities, as well as persons with multiple vulnerabilities. Evaluation of this course also showed promising results, indicating that interactive training methods that make students think and feel, such as face-to-face interaction with vulnerable groups can be effective in changing attitudes and combating stigma and discrimination in healthcare settings [21].

Literature is full of different interventions to reverse stigma and support people/families, who are negatively affected by stigma and discrimination. Some of these anti-stigma interventions are as follows:

1. Awareness raising and educational interventions for the public in general (formal school education, informal education such as peer education, film showing, awareness raising campaigns,etc.)
2. Targeted educational interventions for certain professions (health, education, law, media, etc.)

3. Improving stigmatized populations' access to health care via legal regulations, administrative changes, introducing population specific health services, etc.

4. Interventions to support people/families affected by stigma (social support, self-help or peer groups, online or face-to-face counselling, hotlines, legal support, psychosocial support, medical support, etc.)

5. Scientific studies to understand stigma related dynamics, health effects of stigma and impact of different interventions to reverse stigma

6. Advocacy activities to protect the rights of stigmatized population groups and to support evidence-based policy making [22,23].

In literature, there are numerous examples of such interventions; however, for convenience reasons, this review article will present one intervention example to reduce the effects of stigma towards refugee children in a host country setting.

Side by Side (YanYana)

Side by Side Project was developed for Syrian and Turkish kids aged 7-11 years, teachers working in public schools and therapists (psychologists and psychological counselors) working in public and private institutions in Istanbul. The project was carried out by Bir IZ Association (Association of Trace in Individual and Community Mental Health) in collaboration with Yuva Association, Play Therapies Association, other NGOs and Istanbul Provincial Directorate of National Education. Social impact evaluation was carried out by independent academicians and project experts [24].

The main aims of this Project were 'decreasing discrimination and xenophobia against refugees', 'developing tools to be used for cohesion of Syrian kids and Turkish kids in schools' and 'supporting the well-being of refugee kids by healing their traumas. "Side by Side Psychosocial Support Program for Schools" was applied to 3500 students in Istanbul. The program consisted of interactive activities focused on reducing discrimination and increasing inclusion, as well as playing Side by Side board game. A total of 120 teachers, who implemented the program in schools participated in a 3-day training and received 16 hours of supervision during the 10-week program. In addition, a total of 550 refugee children participated in regular group therapies in 10 weeks period within the scope of Side by Side Group Therapy Program. In total, 73 therapists received a 3-day group leader training and received 60 hours of supervision before leading the group therapies [24].

The project also included advocacy and dissemination activities via news and announcements published on the project web site in three languages (English, Turkish and Arabic), in addition to project's social media accounts and dissemination meetings with the participation of relevant stakeholders including public, civil society, UN representatives from education, social care, migration and health sectors [24]. 
The monitoring and evaluation activities of the project were carried out with a mixed (quantitative and qualitative) methodology by the collaboration of Bir IZ Association experts and independent academicians. In order to compare pre and post intervention variables, control groups for both teachers and students were selected from classes which were not included in the project. Overall, the project had a visible psychosocial impact on teachers, students and the classroom environment. In the group therapy sample, psychologists acquired traumarelated skills during trainings and through working with refugee children. Improvement in refugee students' self-expression and other social skills were observed and safe spaces were created for refugee children. As part of the qualitative evaluation, the classroom pictures, drawn by refugee children, showed a striking difference in how the classrooms were perceived by the children before and after the intervention (Figure 1) [24].

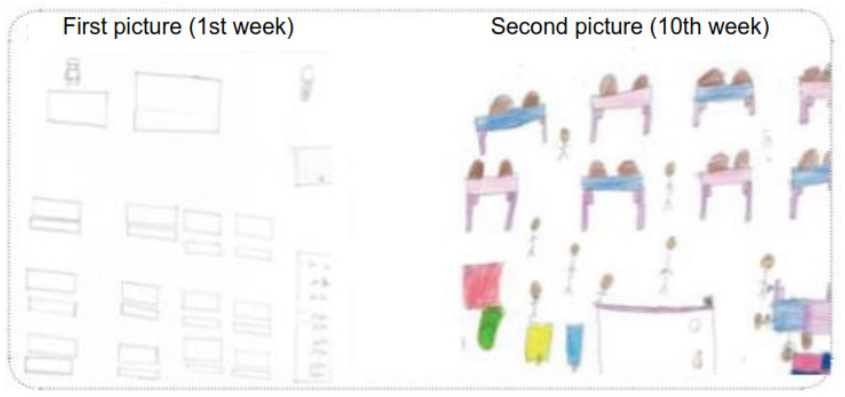

Figure 1. Classroom pictures, drawn by refugee children before and after the intervention (Side by Side Project) [(24]).

\section{DISCUSSION}

Reversing the stigma towards international migrants requires multifaceted, multisectoral and long-term efforts, which should have social, cultural, educational, legal and institutional dimensions. Targeted interventions for key professional groups are essential, however, wider educational interventions that start in pre-school years and aim to build more inclusive societies in a more sustainable way seem more crucial.

Although, migrants are usually defined in a quantitative manner with numbers and not always perceived by host societies as real people, every migrant has a name, story and a dream to live in better conditions. Therefore, reversing the stigma towards migrants should be an integral part of creating healthy living environments, and hence an integral part of health promotion in today's multicultural communities. International migrants need tailored anti-stigma interventions, which need to consider diverse cultural backgrounds [25]. The interventions should also take into consideration that international migrants are not a single homogenous group, but a heterogenous group with different characteristics and needs. Therefore, vulnerabilities and the extent of stigma and discrimination are usually different for different ethnic, religious, gender, and socioeconomic subgroups [26]. In this regard, reaching out to mainstream migrants may be easier than more disadvantaged or more stigmatized migrant groups (e.g. migrants living with HIV, migrants living with a disability), which may require more specific outreach approaches such as working with health mediators, cultural mediators or using peer-to-peer approaches as well as more innovative approaches that make use of digital technologies [27].

Studies consistently show that one of the most important aspects of successful public health interventions is community participation, hence, increasing participation of both migrants and host communities in planning, implementation and evaluation of efforts to combat stigma will not only empower communities, but also strengthen social ties and values to build a shared environment.

Public health professionals have a strong potential to lead such joint initiatives at the local, national or global levels. Public health professionals may play a variety of roles, such as i) conducting qualitative or quantitative studies to assess the level and determinants of stigma towards migrants and the effects of stigma on health and life domains, ii) raising awareness among different population groups, iii) advocating for evidence-based policies and practices to combat stigma and its detrimental effects, iv) designing interventions to reduce stigma and/or its negative effects for individuals and their families, as well as v) disseminating research findings and best practices for wider use at the national, regional and global levels.

\section{Financial Associations/ Conflicts of Interest}

The authors declare no financial associations or any conflict of interest.

\section{Acknowledgement}

The authors would like to thank Dr. Koray Başar and Dr. İrem Yild1z for their efforts in realizing the anti-stigma course for medical students at Hacettepe University, which was shared as one of the inspirational examples of educational interventions in this article. The authors are also thankful to Bir IZ Association for their impactful work and detailed evaluation report for the Side by Side Project.

\section{REFERENCES}

[1] UNHCR Global Appeal 2018-2019. Accessed from https:// www.unhcr.org/en-us/publications/fundraising/5a0c05027/ unhcr-global-appeal-2018-2019-full-report.html on 10 September 2019.

[2] Karadag O, Altintas KH. Refugees and health. TAF Prev Med Bull 2010; 9(1): 55-62.

[3] Link BG, Phelan JC. Conceptualizing stigma. Annual Review of Sociology. 2001;27:363-85. doi:10.1146/annurev. soc.27.1.363.

[4] Türkiye'de Çocuğa Karşı Ayırımcılık Raporu. Gündem Çocuk Derneği Çocuk Hakları İzleme Raporları - 04. Ankara: Gündem Çocuk Derneği, 2014. 
[5] Hatzenbuehler ML. Structural stigma: Research evidence and implications for psychological science. Am Psychol 2016;71[8]:742-51. doi:10.1037/amp0000068

[6] Hatzenbuehler ML, Bellatorre A, Lee Y, Finch BK, Muennig P, Fiscella K. Structural stigma and all-cause mortality in sexual minority populations. Soc Sci Med 2014; 103:33-41.

[7] Quinn DM, Chaudoir SR. Living with a concealable stigmatized identity: The impact of anticipated stigma, centrality, salience, and cultural stigma on psychological distress and Health. J Pers Soc Psychol 2009;97:634-51. doi:10.1037/a0015815.

[8] Youth Friendly Health Services in Humanitarian Settings: Training Manual for Service Providers. Eds: Karadag Caman O. Ankara: UNFPA, Y-PEER Turkey, 2017.

[9] Mason T, Carlisle C, Watkins C, Whitehead E (Eds). Stigma and social exclusion in healthcare. London: Routledge, 2001.

[10] Eccleston, Collette P. The psychological and physical health effects of stigma: the role of self-threats. Soc Personal Psychol Compass 2008; 2:1345-61.

[11] Cabieses B, Bird P. Glossary of access to health care and related concepts for low - and middle-income countries (LMICs): a critical review of international literature. Int J Health Serv 2014;44:845-61.

[12] Karadag Caman O. Mental health as a priority for public health, and a non-priority for policy makers and refugee populations. M8 Alliance Expert Meeting Migrant and Refugee Health, Sapienza University of Rome, June 2019.

[13] Li J, Rose N. Urban social exclusion and mental health of China's rural-urban migrants - A review and call for research. Health Place 2017;48:20-30. doi: 10.1016/j.healthplace.2017.08.009. Epub 2017 Sep 23.

[14] Levison JH, Bogart LM, Khan IF, et al. . "Where It Falls Apart": Barriers to retention in HIV care in latino immigrants and migrants. AIDS Patient Care STDS. 2017 ;31:394-405. doi: 10.1089/apc.2017.0084.

[15] Chen X, Stanton B, Kaljee LM, et al. Social stigma, social capital reconstruction and rural migrants in urban China: A population health perspective. Hum Organ 2011;70:22-32.

[16] Reijneveld SA. Ethnic differences in health and use of health care: the questions to be answered. Int J Public Health 2010; 55:353-5.
[17] Sousa E, Agudelo-Suárez A, Benavides FG, et al. Int J Public Health 2010; 55: 443. https://doi.org/10.1007/ s00038.010.0141-8

[18] Razum O, Spallek J. Addressing health-related interventions to immigrants: migrant-specific or diversity-sensitive? Int J Public Health 2014; 59:893-5.

[19] Karadag Caman O, Uner S. Future physicians' empathic tendency and approach for some community groups. 16th National Public Health Congress, 27-31 October 2013, Antalya/Turkey.

[20] Karabey S, Özgülnar N, Deryol Nacar D, Bayramlar O.F. Tip eğitiminde bir pencere: halk sağlığı, savunmasız gruplar, toplum ve hekim seçmeli staj programı. 19. Ulusal Halk Sağlığ1 Kongresi, 15-19 Mart 2017, Antalya. Kongre Kitabı, 2017:397-398.

[21] Karadag Caman O, Başar K, Mihciokur S. Training of healthcare professionals to reduce stigma and discrimination towards minorities in Turkey. Eur J Public Health 2018, 28 (suppl. 4):269. 11th European Public Health Conference, 28 Nov-1 Dec 2018, Ljubljana/Slovenia. doi: 10.1093/eurpub/ cky213.791

[22] Penn DL, Couture SM. Strategies for reducing stigma toward persons with mental illness. World Psychiatry 2002;1:20-1.

[23] Reducing Stigma and Discrimination Related to HIV and AIDS: Training for Health Care Workers (Participant's Handbook). New York: EngenderHealth, 2004.

[24] Side by Side Project, Bir IZ Association. Accessed from http//:http://www.yanyana.biz/ on 6 July 2019.

[25] Makowski AC, von dem Knesebeck O. Depression stigma and migration - results of a survey from Germany. BMC Psychiatry. 2017 Nov 29;17:381. doi: 10.1186/s12888.017.1549-y.

[26] Larkin M. Vulnerable groups in health and social care. London: Sage Publications, 2009.

[27] Asi YM, Williams C. The role of digital health in making progress toward Sustainable Development Goal (SDG) 3 in conflictaffected populations. Int J Med Inform 2018; 114: 114-20. 